\title{
GERENCIAMENTO DE PORTFÓLIO DE PROJETOS NO SETOR PÚBLICO: UMA REVISÃO DA LITERATURA
}

\section{PROJECT PORTFOLIO MANAGEMENT IN THE PUBLIC SECTOR: A LITERATURE REVIEW}

\author{
Paulo Rafael Minetto Maceta* E-mail: paulo.maceta@gmail.com \\ Fernando Tobal Berssaneti* E-mail: fernando.berssaneti@usp.br \\ Marly Monteiro Carvalho*E-mail: marlymc@usp.br \\ Universidade de São Paulo (USP), São Paulo, SP
}

\begin{abstract}
Resumo: Este estudo tem como objetivo investigar o gerenciamento de portfólio de projetos no contexto do setor público. A abordagem metodológica é a de revisão sistemática da literatura, adotando o método de análise de conteúdo. A amostra é composta de artigos selecionados nas bases de dados ISI Web of Science e Scopus. Os resultados permitiram elaborar um quadro teórico síntese da literatura, em que os conteúdos foram divididos em oito temáticas: portfólio e gerenciamento de portfólio, setor público e nova gestão pública, seleção e priorização, controle, riscos, alinhamento estratégico, problemas do gerenciamento de portfólio e performance e sucesso do portfólio.
\end{abstract}

Palavras-chave: Gerenciamento de Portfólio. Portfólio de Projetos. Setor Público. Governo. Revisão da Literatura.

Abstract: This study aims to investigate the project portfolio management in the public sector's context. The methodological approach is a systematic literature review using the content analysis' method. The sample consists of selected articles in ISI Web of Science and Scopus databases. The results lead to a theoretical framework summarizing the literature which contains eight thematic fields: portfolio and portfolio management, public sector and new public management, selection and prioritization, control, risks, strategic alignment, portfolio management's problems and portfolio's performance and success.

Keywords: Portfolio Management. Project's Portfolio. Public Sector. Government. Literature Review.

\section{INTRODUÇÃO}

As organizações têm como objetivo se desenvolver, independente se forem do setor público ou do setor privado, e, para o desenvolvimento, são necessárias mudanças coordenadas com a estratégia das organizações. Projetos são responsáveis pelas mudanças organizacionais e é a partir deles que ocorre a implantação e o desenvolvimento das estratégias de crescimento (RWELAMILA; PURUSHOTTAM, 2012). Já o gerenciamento de portfólio tem o objetivo de gerenciar os projetos de uma organização, ou seja, garantir que o conjunto certo de projetos seja realizado, alocando para eles os recursos necessários e disponíveis na 
organização, sendo que esse conjunto de projetos e a alocação de recursos deve ser revista e alterada ao longo do tempo com o foco de diminuir os custos dos projetos, minimizar os riscos aos quais a organização está exposta e melhorar os benefícios advindos da execução correta dos projetos (DETTBARN; IBBS; MURPHREE, 2005).

Organizações públicas têm características que as separam das organizações privadas, tais como: não ter a maximização do lucro como objetivo principal, possuir, em sua hierarquia, uma área política que influencia na área administrativa e não ter clareza sobre quais são seus clientes e stakeholders (FRYER; ANTONY; DOUGLAS, 2007). Essas organizações passaram, na década de 1980, por uma reforma na forma com que eram administradas que ficou conhecida como Nova Gestão Pública (NGP), a qual levou ao setor público metodologias, ferramentas e técnicas gerenciais que eram adotadas no setor privado, isso gerou uma quebra do paradigma do setor público, principalmente, em relação aos cidadãos que passaram a serem tratados como clientes.

O gerenciamento de portfólio, apesar de ainda não ser muito adotado pela iniciativa pública, foca nos objetivos estratégicos das organizações, sendo um processo estratégico contínuo com foco nos projetos e atividades estratégicas (PILKAITE்; CHMIELIAUSKAS, 2015), gerando uma correlação com a NGP.

A justificativa e relevância do presente estudo são baseadas em três itens: (1) na importância que o gerenciamento de portfólio de projetos tem para o desenvolvimento e aprimoramento do setor público (CRUZ-REYES et al., 2014, 2015; DUARTE; REIS, 2006; RADNOR; NOKE, 2013); (2) na existência de uma lacuna de pesquisas sobre o tema devido à escassez de artigos, lacuna que é apontada, tanto sobre o gerenciamento de portfólio de projetos no setor público num aspecto amplo por Arlbjørn, Freytag e Thoms (2015), Hansen e Kræmmergaard (2013), Smith et al. (2012) e Young et al. (2012), quanto em um aspecto mais restrito, de áreas específicas, como em Tecnologia da Informação (TI) (NIELSEN; PEDERSEN, 2014) e energia (BAKER; SOLAK, 2014). Tal lacuna também foi identificada na revisão da literatura realizada como demonstrado no item 3 do presente trabalho; e (3) no fato do setor público ainda estar iniciando a adoção do uso do gerenciamento de portfólio (BAKER; SOLAK, 2014) e, portanto, seus resultados ainda levarão algum tempo para serem sentidos (PILKAITE்; CHMIELIAUSKAS, 2015). 
O objetivo do presente trabalho é identificar as estruturas e questões propostas na literatura sobre o tema em foco, identificando as etapas, dificuldades de implantação e outros aspectos relevantes do gerenciamento de portfólio de projetos no setor público. Para tal, a abordagem metodológica adotada foi a de revisão sistemática de literatura, contribuindo para esse campo de pesquisa através do levantamento das definições e práticas adotadas. Isso foi realizado através de uma análise de conteúdo de artigos acadêmicos levantados em dois dos maiores bancos de dados de artigos acadêmicos utilizando parâmetros de buscas amplos.

Esse artigo é estruturado em quatro partes. A primeira apresenta o contexto da pesquisa e seus objetivos. A segunda apresenta a metodologia empregada, seguida pela terceira que descreve os resultados obtidos e apresenta a discussão das temáticas levantadas. A quarta parte apresenta a conclusão do trabalho.

\section{MÉTODOS DE PESQUISA}

Existem diversos tipos de metodologias que podem ser utilizados para uma revisão da literatura tais como a bibliometria, análise de conteúdo e análise semântica. Segundo Randolph (2009), o objetivo da revisão de literatura é integrar e generalizar os achados, sendo utilizada para entender a literatura acadêmica sobre um determinado campo de pesquisa, extrair informações quantitativas e qualitativas sobre os tipos de pesquisa que são feitas sobre o tema e apontar tendências.

A decisão sobre qual tipo de revisão de literatura deve-se utilizar tem relação com os dados levantados, sua quantidade e o nível de maturidade que o campo de pesquisa possui. A análise semântica é utilizada para sintetizar e categorizar termos e expressões gerando uma interpretação coerente dos conceitos (CHEN; IBEKWESANJUAN; HOU, 2010). A bibliometria é uma técnica utilizada para a análise quantitativa da literatura que engloba componentes da matemática, ciências sociais e naturais, analisando citações, co-citações e uma integração de ambas (CHAl; $X I A O, 2012)$, sendo utilizada quando um campo tem um número muito grande de literatura acadêmica para analisar as correlações entre citações, palavras chaves ou outras informações dos artigos. Como exposto por Tsai e Wen (2005), a análise sistemática de conteúdo de artigos auxilia a exploração do tema muito explorado. 


\subsection{Amostragem e coleta dos dados}

Nesse trabalho, uma amostra inicial foi elaborada utilizando duas bases de dados a ISI Web of Science que é uma base de relevância na comunidade acadêmica e a Scopus que é uma base com um espectro maior de periódicos (FALAGAS et al., 2008). Em ambas as bases foi utilizada a mesma busca boleana com os termos: ((("project* manag*" and "portfolio*") or "project* portfolio*" or "portfolio of project" or "portfolio management") AND ("public* sector" or "public* manag*" or "public* polic*" or "public* organi*" or government*)), sendo o símbolo “*” utilizado para que termos parecidos com os buscados (plurais, gerúndios ou substantivos) também fossem encontrados. Foram utilizados somente dois filtros: (a) tipo de documento: "Articles", "Articles in Press" e "Review" e (b) data: de 1980 (década de início da NGP) até 2015.

Essa primeira busca obteve como resultado 115 artigos no Scopus e 67 artigos na ISI Web of Science. Após a constatação que haviam 42 artigos repetidos entre as bases, a mostra inicial contava com 140 artigos.

\subsection{Análise dos dados}

A amostra inicial passou pelo primeiro critério de exclusão: a leitura dos resumos. Esse critério foi utilizado para retirar da amostra os artigos que não tinham ligação com o escopo do presente estudo resultando na exclusão de 105 artigos, gerando uma listagem de 35 artigos. A grande quantidade de exclusões de artigos é devida à proximidade das palavras buscadas com outra área de pesquisa: a gestão de portfólio de investimentos. Dessa última listagem, dois artigos possuíam o texto em línguas que não eram do domínio dos autores (grego e ucraniano) e os autores não obtiveram acesso a outros dois artigos.

Como a listagem final possui 31 artigos, foram descartadas as abordagens bibliométricas e de análise semântica, pois a base de artigos é pequena frente à necessária para a utilização dessas ferramentas. Assim, optou-se pela análise de conteúdo sendo que os textos completos de todos os artigos da listagem final foram lidos e neles identificadas as definições e aplicações do gerenciamento de portfólio de projetos no setor público que foram utilizadas no presente trabalho. 


\section{RESULTADOS E DISCUSSÃO}

Todos os artigos da listagem final foram publicados durante um período de 30 anos entre 1985 e 2015, sendo que 90,3\% dos artigos foram publicados na segunda metade do período. Eles foram publicados em 26 periódicos diferentes, a maioria com somente 1 publicação, somente os periódicos "Construction Management and Economics", "Gestion y Politica Publica", "International Journal of Project Management", "Journal of Information Systems and Technology Management" e "Research Technology Management" tiveram 2 publicações. Um total de 68 autores foram identificados e somente 2 autores produziram mais de um artigo, com 2 artigos cada no campo de pesquisa de gerenciamento de portfólio no setor público. Os artigos foram produzidos por autores de 14 países, sendo que os Estados Unidos tem a maior participação em artigos (8), México a segunda (5), seguido pela Dinamarca com 3 participações. O Brasil tem 2 artigos na lista.

Uma análise das caraterísticas dos artigos aponta para o seguintes fatos: 7 $(22,6 \%)$ dos artigos tem uma abordagem geral do setor público, sem um foco geográfico definido, 7 (22,6\%) analisam o setor público de países em desenvolvimento e $17(54,8 \%)$ analisam o setor público de países desenvolvidos. Em relação ao método de pesquisa: $16(51,6 \%)$ são estudos de caso, $12(38,7 \%)$ são artigos teóricos com modelagens matemáticas ou novos frameworks e $3(9,7 \%)$ são pesquisas do tipo survey. Ainda, 10 (32,3\%) artigos abordam projetos de Pesquisa e Desenvolvimento (P\&D), 6 (19,4\%) de infraestrutura e construção, projetos de TI são abordados por 4 (12,9\%) artigos, outros 4 (12,9\%) artigos abordam outros tipos específicos de projetos e, por fim, 7 (22,6\%) tem uma abordagem genérica em relação ao tipo de projeto.

A seguir serão apresentados os principais tópicos encontrados na revisão bibliográfica e as proposições levantadas.

\subsection{Portfólio e Gerenciamento de Portfólio}

Lee et al. (2008) e Hansen e Kræmmergaard (2013) definem um portfólio de projetos como um conjunto de projetos realizado sob a coordenação de um patrocinador central. Maccari, Martins e Martins (2015) apresentam o mesmo conceito, adicionando que os projetos dentro do portfólio irão competir por recursos Revista Produção Online, Florianópolis, SC, v. 17, n. 1, p. 222-244, jan./mar. 2017. 
(pessoas, finanças, tempo, entre outros) que são escassos e não suficientes para a realização de todos os projetos propostos, assim, serão selecionados projetos que atendam aos requisitos mínimos da organização em determinados critérios.

Young et al. (2012) explicam que o portfólio pode ser considerado como o investimento total que uma organização, pública ou privada, faz em mudanças organizacionais para atingir seus objetivos estratégicos, sendo que as mudanças são realizadas através da execução de projetos. Porém a escolha de um portfólio não pode ser feita analisando seus projetos individualmente, pois um portfólio é uma entidade própria e não a soma de projetos, devido às sinergias e riscos que devem ser considerados de um ponto de vista geral (FERNANDEZ et al., 2006).

Para a construção de um portfólio, a literatura apresenta vários trade-offs que o gerente de portfólio terá, tais como: entre os projetos candidatos (FERNANDEZ et al., 2006) entre as dimensões estratégicas (EILAT; GOLANY; SHTUB, 2006), entre os atributos dos projetos (DUARTE; REIS, 2006) e entre a qualidade e a quantidade de projetos selecionados (LITVINCHEV; LÓPEZ, 2008).

O gerenciamento de portfólio é a administração do portfólio de projetos de uma organização (HANSEN; KRÆEMMERGAARD, 2013) e, para isso, é necessário ter uma estratégia e uma tecnologia bem definida (CÁÑEZ; GARFIAS, 2006). Dettbarn, lbbs e Murphree (2005) expandem o conceito mostrando que o gerenciamento de portfólio é a combinação de fazer a coisa certa com um mix certo de projetos e recursos, ajustando essa combinação ao longo do tempo para minimizar custos e riscos e aumentar os benefícios. Assim, o gerenciamento de portfólio de projetos tem o objetivo de definir o investimento adequado para cada projeto da organização (MACCARI; MARTINS; MARTINS, 2015). A melhoria do uso de recursos e um maior retorno para a organização são apontados por Heindrickson e Santos Jr (2014) como o propósito principal do gerenciamento de portfólio. Quatro atividades do gerenciamento de portfólio são destacadas por Nielsen e Pedersen (2014): identificação do projeto, priorização de projetos, alocação de recursos e realização do portfólio, que se ocupa do monitoramento da execução dos projetos.

O método tradicional de gerenciamento de portfólio, apresentado por Scheinberg e Stretton (1994), pode assumir duas formas: a primeira é chamada de "método de uma linha" aonde cada projeto é representado por uma linha com parâmetros do projeto quantificados, essa abordagem é limitada na capacidade de trabalhar com vários parâmetros como tempo, custos, recursos, entre outros; a Revista Produção Online, Florianópolis, SC, v. 17, n. 1, p. 222-244, jan./mar. 2017. 
segunda forma é a utilização de redes para representar os projetos, aonde o portfólio de projetos é visto como um grande projeto único e o gerenciamento de portfólio é feito utilizando-se das técnicas de gerenciamento de projetos.

Os cinco principais objetivos do gerenciamento de portfólio são apresentados por Anderson (2008), sendo: (1) definir objetivos e metas; (2) analisar e realizar os trade-offs entre os projetos; (3) identificar, eliminar, minimizar e diversificar os riscos; (4) monitorar a performance do portfólio; e (5) atingir os objetivos estratégicos da organização.

Maccari, Martins e Martins (2015) apresentam três aspectos de gestão relacionados com o gerenciamento de portfólio: (1) estratégia: alinhamento de projetos com os objetivos estratégicos da organização; (2) alocação de recursos: alocação de investimentos (financeiros e de pessoas) nos diversos projetos da organização; e (3) seleção de projetos: escolha e priorização dos projetos que assegurem a estratégia e as metas organizacionais. $\mathrm{O}$ alinhamento do portfólio com os objetivos estratégicos deve ser ainda mais forte no setor público, pois ele, segundo Bozeman e Rogers (2001), tem seus projetos e ações definidos por contratos e legislações, o que faz com que a mudança na composição de seu portfólio, como o encerramento ou início de projetos, não possa ser realizado de forma rápida, como no setor privado.

No setor público, para a implantação do gerenciamento de portfólio, o primeiro passo é explicitar para toda a organização o significado do termo e como ele poderá ajudar a organização, após isso, deve-se avançar para um entendimento comum da linguagem utilizada, gerando uma comunicação mais efetiva (PILKAITE்; CHMIELIAUSKAS, 2015). Por outro lado, Benjamin (1985) apresenta a tarefa de criar um portfólio para o setor público também em dois passos, porém com um enfoque mais prático, sendo que, no primeiro passo, o tomador de decisões seleciona as propostas de projetos que estejam melhor alinhadas com os objetivos da organização, depois, esses projetos são planejados, tem suas interdependências reconhecidas e são analisadas as restrições de recursos.

\subsubsection{Seleção e Priorização}

Os problemas de seleção de projetos podem ser decompostos em duas classes: dinâmicos e estáticos. Os dinâmicos são aqueles em que existem propostas Revista Produção Online, Florianópolis, SC, v. 17, n. 1, p. 222-244, jan./mar. 2017. 
de projetos e projetos em andamento para serem escolhidos. Já nos estáticos só existem propostas de projetos (EILAT; GOLANY; SHTUB, 2006).

A modelagem e priorização de um portfólio, de acordo com González e Castillo (2001), se baseiam nas premissas que existe um conjunto de projetos candidatos com características bem definidas e requisitos descritos, e que o portfólio deve ser avaliado por uma medida de qualidade, objetivando maximizar o valor do portfólio levando em conta suas incertezas e riscos. A priorização de projetos deve ser feita por um time multidisciplinar para obter uma visão mais balanceada sobre 0 portfólio, principalmente para projetos de P\&D, pois gerentes de negócios focam no curto prazo, ao passo que gerentes de P\&D focam no longo prazo (CÁÑEZ; GARFIAS, 2006). Bozeman e Rogers (2001) reforçam essa visão, mostrando que no setor público os projetos de P\&D tem um horizonte temporal mais longo que no setor privado.

Os critérios de priorização são abordados por Gabriel, Ordóñez e Faria (2006) que explicam que selecionar projetos com os menores custos ou maiores benefícios é contraproducente, pois a escolha feita de outra forma pode ser mais vantajosa do ponto de vista do custo-benefício, sendo melhor um método que utilize vários fatores de seleção ao mesmo tempo, o que irá gerar uma abordagem de otimização combinatória. A priorização e seleção de projetos necessita que seja definida uma estrutura para a tomada de decisões, estabelecendo sua governança (HEINDRICKSON; SANTOS JR, 2014).

Para servir de base para a seleção e priorização do portfólio em organizações públicas, pode-se dividir os atributos do projeto em qualitativos e quantitativos, ou tangíveis e intangíveis, sendo que esses atributos podem ser separados em dois outros grupos: aqueles que contribuem para quantificar o resultado do projeto e aqueles que contribuem para quantificar a probabilidade de sucesso do projeto (FERNANDEZ et al., 2006; GABRIEL; ORDÓÑEZ; FARIA, 2006; GONZÁLEZ, 2003).

No setor público a priorização tem algumas características próprias. Nielsen e Pedersen (2014) dizem que a priorização é feita por interesse, nos níveis administrativos e políticos, sendo feita através da negociação e influência sobre outros atores, ao que Scheinberg e Stretton (1994) complementam mostrando que os principais parâmetros utilizados para a avaliação de projetos são impostos pelas autoridades ou por contratos entre as partes. Já no estudo de caso de Cáñez e Garfias (2006), as organizações públicas estudadas consideram que a ferramenta Revista Produção Online, Florianópolis, SC, v. 17, n. 1, p. 222-244, jan./mar. 2017. 
para a priorização mais prática é a de pontuação para os projetos, pois é fácil de entender e utilizar. Mulder e Brent (2006) apresentam 4 visões para a priorização: sustentabilidade social, ambiental e econômica e viabilidade técnica, para as quais são utilizados indicadores que são, muitas vezes, qualitativos ou subjetivos.

Lee et al. (2008) mostra que as considerações subjetivas têm muita importância no setor público, pois, se não consideradas, a solução pode não ser aceita pela alta administração.

Apesar da decisão de seleção e priorização de projetos ser tomada no âmbito das áreas administrativas, há, no setor público, um decisor estratégico central que terá a decisão final sobre a priorização de projetos e, normalmente, está no nível político, acima das áreas administrativas (GONZÁLEZ, 2003; NIELSEN; PEDERSEN, 2014). Esse processo é melhor detalhado por Fernandez et al. (2006) que explica que, em organizações públicas, o número de projetos e as áreas de atuação são muito amplos, impossibilitando que o tomador de decisões participe diretamente da avaliação de cada projeto, fazendo com que exista o papel de um agente de decisão (uma pessoa ou grupo) que representa as preferências e prioridades da alta administração, realizando a seleção e priorização dos projetos no lugar do decisor central. Isso é apresentado no estudo de Odeck (2010), que mostra que, na Dinamarca, a priorização de projetos de transporte é feita dentro do ministério (área administrativa), porém ela tem que ser ratificada no parlamento (área política).

A alocação de recursos financeiros em organizações públicas é feito através de seu orçamento, e, tanto Fernandez et al. (2006), quanto Cáñez e Garfias (2006), mostram que o decisor central das organizações irá distribuir os recursos financeiros entre as áreas, por critérios de importância ou retorno da área, para que elas próprias dividam o recurso entre seus projetos internos.

Quatro estilos de tomada de decisão em gerenciamento de portfólios são apresentados por Nielsen e Pedersen (2014): (1) técnica racional; (2) político comportamental; (3) intuição e (4) coincidência, mostrando que o processo de seleção e priorização de projetos nas organizações públicas é caracterizado pela exploração de oportunidades emergentes, através da política, com o uso da intuição e com pouca racionalidade técnica. Vários aspectos diferenciam os processos de decisão do gerenciamento de portfólio em organizações públicas e empresas privadas: (a) os diferentes objetivos das organizações se refletem em uma Revista Produção Online, Florianópolis, SC, v. 17, n. 1, p. 222-244, jan./mar. 2017. 
caracterização distinta dos atributos que determinam o impacto dos resultados; (b) em grandes organizações públicas, o tomador de decisão não participa diretamente da avalição dos projetos e nem na formação do portfólio, delegando sua autoridade para especialistas que atuam em comitês de avalição em suas áreas de conhecimento; (c) no setor privado a avalição dos projetos é detalhada, no setor público a avaliação ocorre determinando somente quais projetos são aceitáveis ou não, posteriormente se utiliza um processo heurístico para distribuir os recursos entre os projetos aceitos e (d) a atitude frente ao risco, sendo que as organizações públicas tem menor aversão ao risco (GONZÁLEZ, 2003).

\subsubsection{Controle}

Existem quatro modelos de controle: controle comportamental, de resultados, de clãs e autocontrole, sendo os dois primeiros formais e os dois últimos informais. O controle comportamental são regras e procedimentos formalizados sendo recompensado o controlado que segue essas regras e procedimentos. O controle de resultados consiste no mecanismo de recompensar com base em resultados, para isso é necessário que os resultados sejam mensuráveis. O controle de clãs consiste no compartilhamento dos mesmos valores, crenças e problemas dentro de um grupo. Os controles formais são melhor comunicados e comparados entre as áreas, mas geram um grande esforço para sua mensuração. Já os controles informais reduzem a burocracia, ao custo do aumento dos esforços individuais (HANSEN; KR/EMMERGAARD, 2013).

O estudo de caso de Griffith (2011) mostra que, ao trabalhar com um portfólio de pequenos projetos no setor público, os métodos de controle devem ser robustos, bem planejados e realizados tanto pela administração pública quanto por empresas contratadas para realizar os serviços. Já no estudo de caso de Pilkaitè e Chmieliauskas (2015), o controle é realizado pelo cargo político que controla o portfólio, sendo que os projetos são executados pelas unidades administrativas. Hansen e Kræmmergaard (2013) ressaltam que o controle formal garante uma avaliação imparcial do gerenciamento de portfólio, mas o que ocorre no setor público é um controle, predominantemente, informal. Bozeman e Rogers (2001) mostram outro aspecto do controle externo no setor público, que é feito pelos clientes e cidadãos, sendo mais forte do que no setor privado.

Revista Produção Online, Florianópolis, SC, v. 17, n. 1, p. 222-244, jan./mar. 2017. 


\subsubsection{Riscos}

Em relação ao gerenciamento de riscos no gerenciamento de portfólio, Cáñez e Garfias (2006) recomendam que se selecione um mix de projetos com riscos altos e baixos, bem como de resultados de curto e longo prazo, mesma visão de Eilat, Golany e Shtub (2006), que, ao analisar projetos de P\&D no setor público, mostram que a diversificação de projetos com riscos diferentes atende melhor os objetivos estratégicos diluindo os riscos dos projetos individuais. Complementarmente, Ofiara e Psuty (2001), atrelando o conceito de riscos com o conceito de incertezas, mostra que o risco de um portfólio é diferente do risco de um projeto individual, quando o risco pode ser mensurado como a variabilidade da ocorrência, já, no contexto do portfólio, o nível de risco global pode ser reduzido selecionando projetos que possuem riscos diferentes. Com o mesmo intuito, Pereira e Veloso (2009) apontam que os riscos devem ser apropriados em relação ao retorno, sendo que a alocação do orçamento deve levar em consideração os riscos. Kulk e Verhoef (2008) mostram que a subdivisão de um projeto em subprojetos pode fazer com que o risco seja melhor gerenciável dentro do portfólio.

\subsection{Alinhamento Estratégico}

Vários autores reforçam a importância do alinhamento do gerenciamento do portfólio com a estratégia, reforçando essa ligação no setor público. González (2003) diz que, em um ambiente globalizado, a seleção correta de projetos é um importante assunto para a indústria e para o desenvolvimento de países emergentes. Assim, o gerenciamento de portfólio é uma ponte que liga a alta administração das organizações e o gerenciamento de projetos (MILLER; EVJE, 1999; YOUNG et al., 2012), sendo os projetos uma forma de criar mudança organizacional e de implantação de estratégias de crescimento (RWELAMILA; PURUSHOTTAM, 2012), sendo que o portfólio de projetos representa, na prática, a visão estratégica das organizações (ROSA; JUNG; MENGDEN, 2013). Esse alinhamento do portfólio com a estratégia pode levar, segundo Munson e Spivey (2006), a uma vantagem competitiva sustentável.

Pilkaitè e Chmieliauskas (2015) mostram que o gerenciamento de portfólio foca nos objetivos estratégicos da organização, sendo visto como um processo Revista Produção Online, Florianópolis, SC, v. 17, n. 1, p. 222-244, jan./mar. 2017. 
estratégico contínuo com foco nos projetos e atividades estratégicos e, apesar da estratégia ser a principal razão pela qual os projetos são iniciados, gerentes de projetos e de portfólios tem um papel passivo na definição da estratégica havendo pouco reconhecimento do papel empreendedor que eles devem ter no ajuste da estratégia (YOUNG et al., 2012).

O gerenciamento de portfólio tem se tornado importante no setor público, pois a maioria das decisões que afetam a estratégia das organizações públicas são implantadas através de um portfólio de projetos complexos (PILKAITE்; CHMIELIAUSKAS, 2015). Além disso, os portfólios ajudam as organizações a focarem nos objetivos de longo prazo (MUNSON; SPIVEY, 2006), e, como o setor público tem objetivos com um prazo maior que o privado, o alinhamento do gerenciamento de portfólio com o setor público é grande.

Essas discussões permitem deduzir a seguinte proposição:

Proposição 1 (P1) - Um bom alinhamento estratégico tem impacto positivo no gerenciamento de portfólio.

\subsection{Performance, Sucesso e Problemas do Portfólio}

\subsubsection{Performance e Sucesso do Portfólio}

Eilat, Golany e Shtub (2006) explicam que a avaliação da performance de um portfólio não é limitada à lucratividade, requerendo que se considerem múltiplos critérios, vários dos quais envolvem incertezas e dados subjetivos. Para Mulder e Brent (2006) o uso de critérios de seleção adequados aumenta significativamente a chance de sucesso, porém não geram a garantia de sucesso do portfólio. Já Dettbarn, lbbs e Murphree (2005) afirmam que o sucesso do gerenciamento de portfólio melhora a performance do negócio, seja público ou privado. Moraes e Laurindo (2013) demonstram uma relação entre a maturidade do gerenciamento de projetos da organização com o sucesso dos projetos, o que irá impactar no sucesso do portfólio.

A performance do portfólio no setor público é analisada por González e Castillo (2001) que mostram que o setor público trabalha com projetos que são de longo prazo, sendo seu sucesso de difícil mensuração, este é o caso dos projetos de pesquisa pura, desenvolvimento educacional e saúde. A performance de projetos no Revista Produção Online, Florianópolis, SC, v. 17, n. 1, p. 222-244, jan./mar. 2017. 
setor público é medida através de aspectos financeiros, econômicos, sociais e políticos, caso a preferência da organização pública seja nos aspectos financeiros e econômicos, seu foco será em projetos de infraestrutura que são comercialmente e economicamente viáveis e darão sustentabilidade para o crescimento da organização no longo prazo, mas, caso a preferência seja para objetivos sociais, o foco será em projetos que distribuam riquezas entre os cidadãos (BENJAMIN, 1985).

Em organizações sem fins lucrativos, como as organizações públicas, há uma forte importância das medidas qualitativas e subjetivas para a medição da performance de um portfólio, o que faz com que vários resultados sejam incomparáveis, inexistindo como combiná-los em um único número que meça a eficácia geral. Isso decorre do fato que medidas qualitativas não serem estimadas com precisão sendo ligadas a incertezas (EILAT; GOLANY; SHTUB, 2006). Odeck (2010) mostra que as métricas de resultado no setor público não podem ser quantificadas em medidas monetárias, apesar de Bozeman e Rogers (2001) apresentarem a taxa de retorno financeiro como uma métrica utilizada no setor público. Importante notar que, no setor público, o sucesso do portfólio é correlacionado, positivamente, com o apoio dos gerentes de projetos e da alta administração (MUNSON; SPIVEY, 2006).

Um dos objetivos do gerenciamento de portfólios no setor público, apresentado por Benjamin (1985), é garantir a melhor contribuição para o desenvolvimento do crescimento econômico, distribuição de riqueza e aumento da autossuficiência da organização. Baker e Solak (2014) definem o sucesso do portfólio no setor público como a maximização da utilidade social esperada. Complementarmente, Rwelamila e Purushottam (2012) mostram evidências de correlação entre o sucesso no gerenciamento de portfólio e o sucesso futuro de organizações públicas, o que gera melhorias para os cidadãos e políticas sustentáveis. Essas definições de sucesso no setor público geram uma dificuldade na medição da performance em organizações públicas, pois o impacto potencial de um projeto proposto pode não ser determinado, sendo um reflexo da conformidade com um conjunto de diretrizes (MULDER; BRENT, 2006).

Essas discussões permitem deduzir a seguinte proposição:

Proposição 2a (P2a) - Um bom gerenciamento de portfólio tem impacto positivo na performance e sucesso do portfólio. 


\subsubsection{Problemas do Gerenciamento de Portfólio}

A literatura apresenta vários problemas que podem haver no gerenciamento de portfólio. Nielsen e Pedersen (2014) explicitam que os problemas de portfólio são parecidos no setor público e privado, sendo que nem todas as técnicas de gerenciamento de portfólio são utilizadas, pois elas são muito complexas. Já Hansen e Kræmmergaard (2013) propõem que alguns problemas de portfólio do setor público advêm das maiores barreiras que as organizações governamentais possuem para atingir uma transformação da governança nos aspectos relacionais, gerenciais e tecnológicos.

Rwelamila e Purushottam (2012) apontam que tanto o setor público quanto o setor privado normalmente empregam uma abordagem ruim, na qual a equipe de planejamento da organização identifica os projetos e depois os passa para um grupo de gerenciamento de projetos para que eles os executem, sendo que essa equipe não é uniforme e nem foi envolvido na seleção dos projetos. Essa abordagem não funciona, pois, para obter sucesso nos projetos, é necessário que os funcionários internalizem a importância da seleção de projetos.

Os estudos de caso de Nielsen e Pedersen (2014) demonstram que a implantação do gerenciamento de portfólio no setor público enfrenta alguns problemas como a falta de projetos formalizados e a ingerência política, a qual força os gerentes de portfólio a trafegarem tanto no ambiente político quanto no ambiente administrativo, pois as considerações políticas são importantes para a priorização dos projetos, sendo que um dos critérios de priorização é não selecionar projetos que, caso tenham uma má performance, afetarão negativamente o ambiente político.

Os problemas listados pela literatura de gerenciamento de portfólio no setor público são: fraca priorização; início simultâneo de vários projetos; desenvolvimento de projetos com baixo valor; atingimento de benefícios inadequados (NIELSEN; PEDERSEN, 2014); fraco planejamento (MULDER; BRENT, 2006); tratamento inadequado das inter-relações entre projetos (EILAT; GOLANY; SHTUB, 2006); fraco processo de responsabilização entre os níveis político, administrativo e executivo; projetos estabelecidos com informações incompletas sobre os recursos internos; falta de objetivos operacionais; falta de contabilidade dos custos de projetos (HANSEN; KRÆMMERGAARD, 2013); uso de poder excessivo e de Revista Produção Online, Florianópolis, SC, v. 17, n. 1, p. 222-244, jan./mar. 2017. 
política, que faz com que sejam priorizados projetos que contemplem interesses próprios de membros da organização pública; falta de urgência na execução e implantação de projetos; falta do gerenciamento estratégico de processo (RWELAMILA; PURUSHOTTAM, 2012); não participação do tomador de decisão na avaliação dos projetos; os processos de avaliação e de formação do portfólio se baseiam em visões falhas resultando em soluções factíveis, porém não ótimas (GONZÁLEZ, 2003); falha na modelagem das preferencias, crenças e prioridades da alta administração para a seleção de projetos; falha na medição da qualidade de um portfólio; falha na exploração das lacunas de portfólio; falha no entendimento do conhecimento contido em dados históricos que descrevem as características desejáveis para projetos e a imprecisão relacionada com os requisitos de financiamento (FERNANDEZ et al., 2006).

Essas discussões permitem deduzir a seguinte proposição:

Proposição 2b (P2b) - Um bom modelo de gerenciamento de portfólio reduz os problemas do gerenciamento de portfólio.

\subsection{Setor Público e Nova Gestão Pública}

De acordo com Fryer, Antony e Douglas (2007) o setor público consiste em organizações que entregam bens e serviços do governo no nível local e nacional. Alguns pontos chave que caracterizam o setor público são: (1) embora existam controles e objetivos financeiros, o objetivo principal não é maximizar o lucro; (2) existem áreas distintas de política, gerenciamento e serviços profissionais que tem que negociar entre si; (3) há uma falta de clareza sobre seus clientes; (4) existem vários stakeholders, entre eles, os próprios clientes; (5) o gerenciamento da organização está sujeito às vontades políticas e, quando ocorre uma troca da administração, pode ocorrer uma reorganização da organização. Uma diferença entre os setores é que no privado, o resultado financeiro e a motivação do lucro geram uma base para a medição do valor esperado e da performance da organização, e, no público, o valor está baseado nos desejos e percepções dos indivíduos sendo que a organização pública deve operar de acordo com eles. Gestores públicos procuram satisfazer os stakeholders a que sua organização responde sendo responsáveis por produzir medidas que mostrem o atingimento das metas e objetivos (DETTBARN; IBBS; MURPHREE, 2005).

Revista Produção Online, Florianópolis, SC, v. 17, n. 1, p. 222-244, jan./mar. 2017. 
Os objetivos da administração pública são apresentados por Duarte e Reis (2006) como sendo maximizar: (1) a inovação; (2) o impacto geográfico (economia de escala); (3) a conexão entre parceiros e habilidades (efeito de rede); (4) o número de beneficiários diretos; (5) o número de agentes beneficiados indiretamente; (6) as habilidades técnicas; (7) a eficiência econômica (sustentabilidade econômica) e (8) as sinergias entre as ações (integração de projetos). Já Arlbjørn, Freytag e Thoms (2015) apresentam o foco da NGP resumido em três aspectos: explicitar os objetivos, focar nas saídas e usar os recursos de forma eficiente.

Um aspecto relevante do setor público, segundo Arlbjørn, Freytag e Thoms (2015), é que a falta de mecanismos de mercado gera a necessidade de um gerenciamento político das prioridades e objetivos da organização, o que origina múltiplos objetivos, sendo que são, muitas vezes, de difícil conciliação, o que faz com que o resultado do setor público seja de difícil mensuração.

Assim como no setor privado, a administração pública, segundo Pilkaitè e Chmieliauskas (2015), sofre pressão de seus stakeholders para produzir performance e transparência, com o intuito de tomar decisões que sejam responsáveis e razoáveis em relação ao gasto do dinheiro dos impostos e a melhoria da efetividade dos serviços prestados ao cidadão. Essa pressão fez com que o setor público passasse por uma grande mudança no fim da década de 1980 substituindo um modelo mais burocrático pela NGP, um movimento de modernização do aparelho estatal, aonde o cidadão deixa o papel de contribuinte para assumir o papel de cliente-cidadão, alterando o foco da gestão pública mais para resultados do que para processos internos (RADNOR; NOKE, 2013). A NGP é relevante tanto para o setor público quanto para o privado, pois ela é uma abordagem que utiliza técnicas de gerenciamento do setor privado no setor público melhorando sua eficiência e resultados (YOUNG et al., 2012). Uma ligação entre a NGP e o gerenciamento de portfólios é feita por Pilkaitè e Chmieliauskas (2015) que apontam algumas das características da reforma organizacional gerada pela NGP, como a especialização, coordenação, descentralização de funções e mudança no escopo, também se relacionam ao gerenciamento de portfólio.

Nielsen e Pedersen (2014) apresentam o governo eletrônico ou e-government como a próxima grande reforma no setor público após a NGP, assumindo que a forma com que o setor público administra suas decisões de portfólio tem impacto no resultado dos investimentos no governo eletrônico. Opinião corroborada por Hansen Revista Produção Online, Florianópolis, SC, v. 17, n. 1, p. 222-244, jan./mar. 2017. 
e Kræmmergaard (2013), que mostram a importância crescente do portfólio de TI nas organizações públicas para atingir um maior grau de maturidade do governo eletrônico.

Essas discussões permitem deduzir a seguinte proposição:

Proposição 3 (P3) - As características singulares das organizações públicas impactam tanto o tipo de gerenciamento de portfólio quanto o seu desempenho.

\subsection{Quadro Teórico de Síntese da Revisão Sistemática da Literatura}

Após a análise de conteúdo realizada na revisão da literatura apresentada acima, foi possível identificar as principais temáticas, quais sejam: gerenciamento de portfólio, seleção e priorização, controle, riscos, alinhamento estratégico, performance e sucesso do portfólio, problemas do gerenciamento de portfólio e setor público e a nova gestão pública. De acordo com essas temáticas levantadas na análise da literatura, foi proposto um quadro teórico de síntese, conforme Figura 1, onde as temáticas estão identificadas com os números correspondentes da seção do artigo na qual foram apresentadas e as proposições estão indicadas nas setas relacionadas com as temáticas que as influenciam.

Figura 1 - Quadro Teórico Síntese da Revisão Sistemática da Literatura

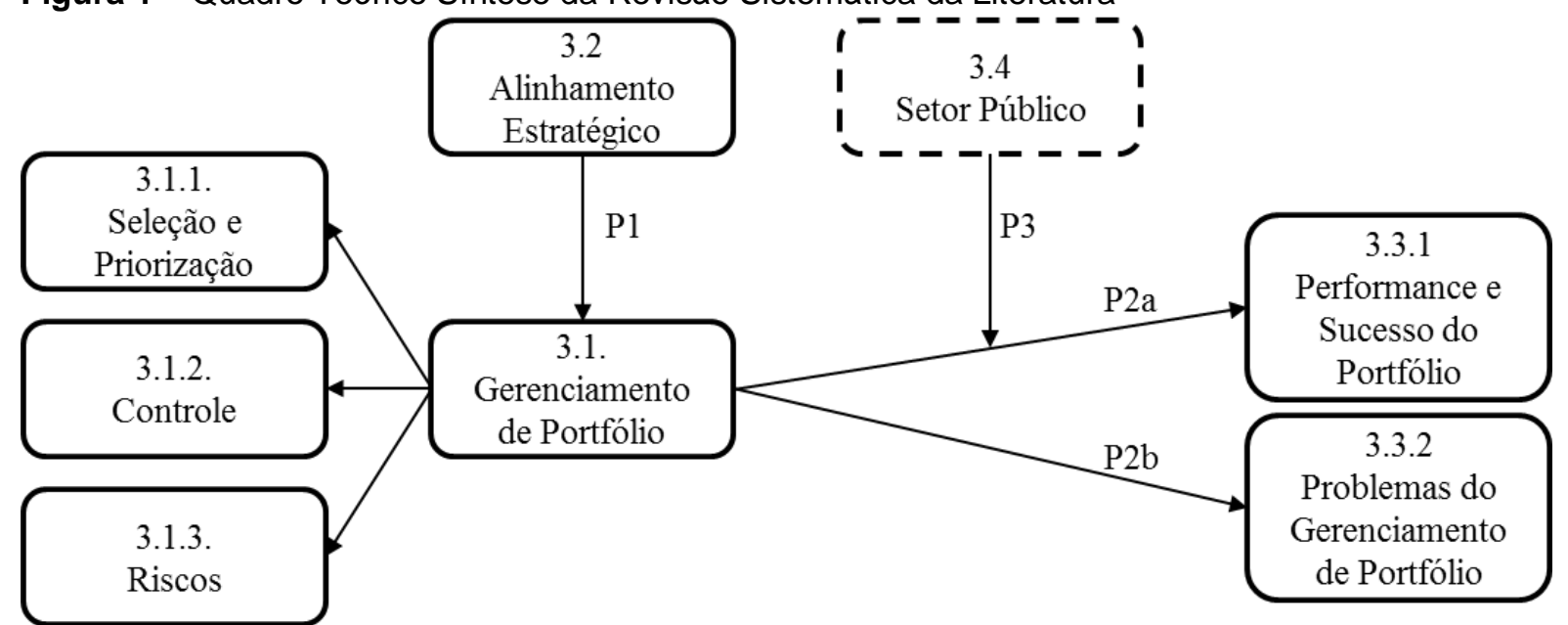

Fonte: Elaborado pelos autores

$\mathrm{Na}$ Figura 1, foi possível identificar, duas variáveis latentes a montante, Alinhamento Estratégico e Gerenciamento de Portfólio (GP). A variável GP é de segunda ordem composta por três variáveis latentes de primeira ordem: seleção e priorização, controle e risco. A jusante no modelo tem-se duas variáveis Revista Produção Online, Florianópolis, SC, v. 17, n. 1, p. 222-244, jan./mar. 2017. 
dependentes: performance e sucesso do portfólio e problemas do gerenciamento de portfólio. Finalmente, a variável moderadora "setor público" busca identificar as características singulares desse tipo de organização. Com base na análise de conteúdo, foi possível estabelecer as 4 proposições apresentadas ao longo da revisão da literatura:

Proposição 1 (P1) - Um bom alinhamento estratégico tem impacto positivo no gerenciamento de portfólio.

Proposição 2a (P2a) - Um bom gerenciamento de portfólio tem impacto positivo na performance e sucesso do portfólio.

Proposição 2b (P2b) - Um bom modelo de gerenciamento de portfólio reduz os problemas do gerenciamento de portfólio.

Proposição 3 (P3) - As características singulares das organizações públicas impactam tanto o tipo de gerenciamento de portfólio quanto o seu desempenho.

\section{CONCLUSÕES}

Este estudo contribuiu para a literatura de gerenciamento de portfólio no contexto do setor público de duas maneiras. Primeiro, foi feita uma varredura nas principais bases científicas de dados, o que permitiu fazer uma análise em profundidade do tema. Segundo, foi possível chegar a um quadro teórico síntese da literatura (ver Figura 1) que pode contribuir nas pesquisas futuras sobre o tema. Esse quadro também tem implicações para a prática, dado que pode ajudar gestores de instituições públicas a refletir sobre o gerenciamento de portfólio.

As definições de projetos no setor público e no setor privado não diferem, sendo um conjunto de projetos que irão competir por recursos, sendo que eles serão escassos para a realização de todos os projetos simultaneamente. As diferenças entre os setores ocorrem devido ao setor público não ter como objetivo principal aumentar a lucratividade, ter em sua estrutura um forte componente político que influenciará em suas atividades e não ter clientes nem stakeholders claramente definidos. Porém no setor público também há uma forte pressão dos stakeholders para que a performance seja melhor e mais transparente, bem como que o dinheiro público seja bem gasto com projetos que atinjam os objetivos estratégicos das organizações públicas. 
O gerenciamento de portfólio auxilia as organizações públicas no contexto da NGP, pois ele torna a administração pública mais eficiente e mais apta a desenvolver os melhores projetos. A continuação dessa evolução passa a ser 0 governo eletrônico, que, por se basear em recursos de tecnologia da informação, encontra no gerenciamento de portfólio de projetos um aliado, reforçando a importância do gerenciamento de portfólio no setor público. Apesar disso, a análise dos artigos selecionados aponta uma predominância de artigos mais recentes e de abordagem mais teórica e qualitativa, demonstrando um campo de pesquisa ainda em desenvolvimento.

O gerenciamento de portfólio no setor público segue, em sua maior parte, as metodologias tradicionais aplicadas no setor privado, principalmente a divisão das atividades em: identificação e priorização de projetos, alocação de recursos e realização do portfólio. Porém na seleção e priorização dos projetos o setor público se baseia em critérios que medem o impacto do projeto e, também, que quantifiquem a possibilidade do sucesso do projeto. Essa priorização muitas vezes é feita de forma política, sendo que a decisão inicia nas áreas administrativas e vai para a área política, aonde um decisor central tomará a decisão final sobre o portfólio, apesar de, durante a análise dos projetos candidatos, o decisor central possa delegar essa análise a uma pessoa (ou grupo) de sua confiança, devido a amplitude dos temas tratados. Isso mostra outro fator importante da decisão sobre o portfólio no setor público, que ela é, muitas vezes, feita com pouca racionalidade técnica.

O controle dos projetos do portfólio no setor público, apesar da literatura recomendar que seja forte, é exercido de maneira predominantemente informal. Isso ocorre apesar da importância demonstrada pelo portfólio de traduzir a estratégia da organização pública.

Por fim, os problemas do gerenciamento de portfólio no setor público se concentram nas ingerências políticas que ocorrem durante todo o processo, disso decorre uma fraca priorização, um fraco planejamento e um tratamento inadequado das inter-relações entre os projetos, acarretando uma falha na performance do portfólio. Os projetos do setor público, normalmente, são projetos de longo prazo, o que torna seu sucesso de difícil mensuração, pois é necessário o uso de indicadores qualitativos e até subjetivos tornando sua performance pouco comparável com outros projetos.

Revista Produção Online, Florianópolis, SC, v. 17, n. 1, p. 222-244, jan./mar. 2017. 
O presente estudo tem como principal limitação o alcance dos artigos analisados, que apesar de terem sido utilizados termos de pesquisas amplos em duas das maiores bases de dados de literatura acadêmica, a pesquisa pode não ter coberto a totalidade de artigos sobre o assunto.

\section{REFERÊNCIAS}

ANDERSON, T. E. Making GIG Information Assurance Better Through Portfolio Management. CrossTalk, v. 21, n. 7, p. 9-11, 2008.

ARLBJØRN, J. S.; FREYTAG, P. V.; THOMS, L. Portfolio management of development projects in Danish municipalities. International Journal of Public Sector Management, v. 28, n. 1, p. 11-28, 2015. http://dx.doi.org/10.1108/IJPSM-03-2014-0047

BAKER, E.; SOLAK, S. Management of energy technology for sustainability: How to fund energy technology research and development. Production and Operations Management, v. 23, n. 3, p. 348-365, 2014. http://dx.doi.org/10.1111/poms.12068

BENJAMIN, C. O. A Linear Goal-Programming Model for Public-Sector Project Selection. The Journal of the Operational Research Society, v. 36, n. 1, p. 13-23, 1985. http://dx.doi.org/10.1057/jors.1985.3

BOZEMAN, B.; ROGERS, J. Strategic management of government-sponsored R and D portfolios. Environment and Planning C: Government and Policy, v. 19, n. 3, p. 413-442, 2001. http://dx.doi.org/10.1068/c1v

CÁÑEZ, L.; GARFIAS, M. Portfolio Management at the Mexican Petroleum Institute. Research Technology Management, v. 49, n. 4, p. 46-55, 2006.

CHAI, K.-H.; XIAO, X. Understanding design research: A bibliometric analysis of Design Studies (1996-2010). Design Studies, v. 33, n. 1, p. 24-43, 2012. http://dx.doi.org/10.1016/..destud.2011.06.004

CHEN, C.; IBEKWE-SANJUAN, F.; HOU, J. The structure and dynamics of cocitation clusters: A multiple-perspective cocitation analysis. Journal of the American Society for Information Science and Technology, v. 61, n. 7, p. 1386-1409, 2010. http://dx.doi.org/10.1002/asi.21309

CRUZ-REYES, L. et al. A Decision Support System Framework for Public Project Portfolio Selection with Argumentation Theory. Studies in Computational Intelligence, v. 547, p. 467-479, 2014. http://dx.doi.org/10.1007/978-3-319-05170-3 32

CRUZ-REYES, L. et al. Simplification of Decision Rules for Recommendation of Projects in a Public Project Portfolio. Studies in Computational Intelligence, v. 601, p. 419-429, 2015. http://dx.doi.org/10.1007/978-3-319-17747-2 31

DETTBARN, J. L.; IBBS, C. W.; MURPHREE, E. L. Capital Project Portfolio Management for Federal Real Property. Journal of Management in Engineering, v. 21, n. 1, p. 44-53, 2005. http://dx.doi.org/10.1061/(ASCE)0742-597X(2005)21:1(44) 
DUARTE, B. P. M.; REIS, A. Developing a projects evaluation system based on multiple attribute value theory. Computers \& Operations Research, v. 33, n. 5, p. 1488-1504, 2006. http://dx.doi.org/10.1016/j.cor.2004.11.003

EILAT, H.; GOLANY, B.; Shtub, A. Constructing and evaluating balanced portfolios of R\&D projects with interactions: A DEA based methodology. European Journal of Operational Research, v. 172, n. 3, p. 1018-1039, 2006. http://dx.doi.org/10.1016/j.ejor.2004.12.001

FALAGAS, M. E. et al. Comparison of PubMed, Scopus, Web of Science, and Google Scholar: strengths and weaknesses. The FASEB journal, v. 22, n. 2, p. 338-342, 2008. http://dx.doi.org/10.1096/fj.07-9492LSF

FERNANDEZ, E. et al. Intelligent Techniques for R\&D Project Selection in Large Social Organizations. Computación y Sistemas, v. 10, n. 1, p. 28-56, 2006.

FRYER, K. J.; ANTONY, J.; DOUGLAS, A. Critical success factors of continuous improvement in the public sector: A literature review and some key findings. The TQM Magazine, v. 19, n. 5, p. 497-517, 2007. http://dx.doi.org/10.1108/09544780710817900

GABRIEL, S. A.; ORDÓÑEZ, J. F.; FARIA, J. A. Contingency Planning in Project Selection Using Multiobjective Optimization and Chance Constraints. Journal of Infrastructure Systems, v. 12, n. 2, p. 112-120, 2006. http://dx.doi.org/10.1061/(ASCE)1076$\underline{0342(2006) 12: 2(112)}$

GONZÁLEZ, E. F. Analysis of the decision to assess and form $R$ and D project portfolios: A critical and suggesting approach. Gestion y Politica Publica, v. 12, n. 1, p. 43-79, 2003.

GONZÁLEZ, E. F.; CASTILLO, J. N. Model and decision support system for portfolio problems in projects of social importance. Gestion y Politica Publica, v. 10, n. 1, p. 31-52, 2001.

GRIFFITH, A. Delivering best value in the small works portfolio of public sector organizations when using preferred contractors. Construction Management and Economics, v. 29, n. 9, p. 891-900, 2011. http://dx.doi.org/10.1080/01446193.2011.617377

HANSEN, L. K.; KRAEMMERGAARD, P. Transforming local government by project portfolio management: Identifying and Overcoming Control Problems. Transforming Government: People, Process and Policy, v. 7, n. 1, p. 50-75, 2013.

http://dx.doi.org/10.1108/17506161311308160

HEINDRICKSON, G.; SANTOS JR, C. D. Information Technology Governance in Public Organizations: How Perceived Effectiveness Relates To Three Classical Mechanisms. Journal of Information Systems and Technology Management, v. 11, n. 2, p. 297-326, 2014. http://dx.doi.org/10.4301/S1807-17752014000200005

KULK, G. P.; VERHOEF, C. Quantifying requirements volatility effects. Science of Computer Programming, v. 72, n. 3, p. 136-175, 2008.

http://dx.doi.org/10.1016/j.scico.2008.04.003

LEE, S. et al. Applying technology road-maps in project selection and planning. International Journal of Quality \& Reliability Management, v. 25, n. 1, p. 39-51, 2008. http://dx.doi.org/10.1108/02656710810843568 
LITVINCHEV, I.; LÓPEZ, F. An interactive algorithm for portfolio bi-criteria optimization of R\&D projects in public organizations. Journal of Computer and Systems Sciences International, v. 47, n. 1, p. 25-32, 2008. http://dx.doi.org/10.1007/s11488-008-1004-0

MACCARI, E. A.; MARTINS, S. B.; MARTINS, C. B. Multi-Criteria Project Priorization in a Professional Master's Program. Journal of Information Systems and Technology Management, v. 12, n. 2, p. 393-414, 2015. http://dx.doi.org/10.4301/S180717752015000200011

MILLER, J. B.; EVJE, R. H. The practical application of delivery methods to project portfolios. Construction Management and Economics, v. 17, n. 5, p. 669-677, 1999. http://dx.doi.org/10.1080/014461999371277

MORAES, R. O.; LAURINDO, F. J. B. Relações entre o desempenho dos projetos de TI e a maturidade em gestão de projetos. Produção Online, v. 13, n. 1, p. 61-83, 2013. http://dx.doi.org/10.14488/1676-1901.v13i1.1027

MULDER, J.; BRENT, A. C. Selection of Sustainable Rural Agriculture Projects in South Africa: Case Studies in the LandCare Programme. Journal of Sustainable Agriculture, v. 28, n. 2, p. 55-84, 2006. http://dx.doi.org/10.1300/J064v28n02 06

MUNSON, J. M.; SPIVEY, W. A. Take a portfolio view of Cradas. Research Technology Management, v. 49, n. 4, p. 39-45, 2006.

NIELSEN, J. A.; PEDERSEN, K. IT portfolio decision-making in local governments: Rationality, politics, intuition and coincidences. Government Information Quarterly, v. 31, n. 3, p. 411-420, 2014. http://dx.doi.org/10.1016/i.giq.2014.04.002

ODECK, J. What Determines Decision Makers' Preferences for Road Investments? Evidence from the Norwegian Road Sector. Transport Reviews, v. 30, n. 4, p. 473-494, 2010. http://dx.doi.org/10.1080/01441640903138640

OFIARA, D. D.; PSUTY, N. P. Suitability of Decision-Theoretic Models to Public Policy Issues Concerning the Provision of Shoreline Stabilization and Hazard Management. Coastal Management, v. 29, n. 4, p. 271-294, 2001. http://dx.doi.org/10.1080/089207501750475109

PEREIRA, P. L.; VELOSO, F. M. R\&D activity selection process: Building a strategy-aligned R\&D portfolio for government and nonprofit organizations. IEEE Transactions on Engineering Management, v. 56, n. 1, p. 95-105, 2009. http://dx.doi.org/10.1109/TEM.2008.2009872

PILKAITÉ, A.; CHMIELIAUSKAS, A. Changes in Public Sector Management: Establishment of Project Management Offices - A Comparative Case Study of Lithuania and Denmark. Public Policy and Administration, v. 14, n. 2, p. 291-306, 2015. http://dx.doi.org/10.13165/VPA-15-14-2-10

RADNOR, Z. J.; NOKE, H. Conceptualising and contextualising public sector operations management. Production Planning \& Control: The Management of Operations, v. 24, n. 10-11, p. 867-876, 2013. http://dx.doi.org/10.1080/09537287.2012.666884

RANDOLPH, J. J. A Guide to Writing the Dissertation Literature Review. Practical Assessment, Research \& Evaluation, v. 14, n. 13, 2009. 
ROSA, F. L.; JUNG, C. F.; MENGDEN, P. R. Um modelo para avaliação do potencial estratégico de projeto de P\&D de inovação tecnológica. Produção Online, v. 13, n. 3, p. 1167-1196, 2013. http://dx.doi.org/10.14488/1676-1901.v13i3.1421

RWELAMILA, P. D.; PURUSHOTTAM, N. Project Management Trilogy Challenges in AfricaWhere to From Here? Project Management Journal, v. 43, n. 4, p. 5-13, 2012. http://dx.doi.org/10.1002/pmj.21278

SCHEINBERG, M.; STRETTON, A. Multiproject planning: tuning portfolio indices. International Journal of Project Management, v. 12, n. 2, p. 107-114, 1994. http://dx.doi.org/10.1016/0263-7863(94)90017-5

SMITH, P. et al. Budget-constrained portfolio trades using multiobjective optimization.

Systems Engineering, v. 15, n. 4, p. 461-470, 2012. http://dx.doi.org/10.1002/sys.21212

TSAI, C.-C.; WEN, M. L. Research and trends in science education from 1998 to 2002: a content analysis of publication in selected journals. International Journal of Science Education, v. 27, n. 1, p. 3-14, 2005. http://dx.doi.org/10.1080/0950069042000243727

YOUNG, R. et al. Is strategy being implemented through projects? Contrary evidence from a leader in New Public Management. International Journal of Project Management, v. 30, n. 8, p. 887-900, 2012. http://dx.doi.org/10.1016/j.ijproman.2012.03.003

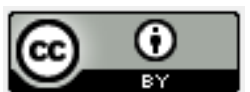

Artigo recebido em 15/04/2016 e aceito para publicação em 01/12/2016

DOI: http://dx.doi.org/10.14488/1676-1901.v17i1.2428 